\title{
LudIE - Grupo de Pesquisa, Desenvolvimento e Aplicação de Jogos Educacionais
}

\author{
Vanessa Dantas ${ }^{1}$, Ayla Dantas Rebouças ${ }^{1}$, Thaíse K. L. Costa ${ }^{1}$, Pasqueline Dantas \\ Scaico $^{1}$, Ana Liz Souto O. Araújo ${ }^{1}$ \\ ${ }^{1}$ Departamento de Ciências Exatas - Centro de Ciências Aplicadas e Educação - \\ Universidade Federal da Paraíba (UFPB) - Rua da Mangueira, s/n - CEP 58.297 - 000 - \\ Rio Tinto - PB - Brasil \\ \{vanessa, ayla, thaise, pasqueline, analiz\}@dce.ufpb.br
}

Jogos educacionais são apontados por diversos autores como um instrumento pedagógico útil e estratégico para o aprendizado de conteúdos curriculares. Nesse contexto, o grupo Ludie tem por objetivo promover projetos de pesquisa, desenvolvimento e aplicação de jogos educacionais ligados a assuntos da área de Computação e também a disciplinas do Ensino Básico.

O grupo é composto pelas professoras Vanessa Dantas, Ayla Dantas Rebouças, Thaíse Costa, Pasqueline Dantas Scaico e Ana Liz Souto O. Araújo, todas alocadas na Universidade Federal da Paraíba, Campus IV, na cidade de Rio Tinto - PB. Ele conta também com a participação de alunos do Curso de Licenciatura em Ciência da Computação da UFPB, integrantes de projetos institucionais como PIBID e PIBIC da Capes, ProExt do MEC, assim como Prolicen e PROBEX da UFPB.

São várias as contribuições do Ludie para a área de ensino de programação, merecendo destaque os jogos ProGame e Castelo dos Enigmas, já concluídos e destinados aos aprendizes de lógica de programação, e os jogos em desenvolvimento Klouro, Python Puzzle, Entrando Pelo Cano, e Robotimov, todos para apoiar o ensinoaprendizagem de Python.

O grupo também tem trabalhos relacionados ao ensino de outros conceitos computacionais, como o jogo Pense Bem, que introduz conceitos de roteamento e bloqueio de redes para alunos do ensino fundamental, o jogo Sokobin, que trabalha conceitos do sistema de numeração binário, e o jogo Starvation, ainda em desenvolvimento, focado em análise de sentenças e de expressões booleanas.

Com foco no Ensino Básico, quatro jogos já foram criados: PyQuímica, para ensino de química; PyGonometria, para ensino de trigonometria; PyLavra, para alfabetização; e Ethereal, para ensino de conceitos matemáticos). Outros dois jogos (\%PORCENTO\% - operações matemáticas, e Vamos às Compras - formação de palavras) estão em desenvolvimento.

Além de produzir jogos educacionais, a equipe se dedica ainda à aplicação de jogos de terceiros, com experiências bem sucedidas nos projetos Gincana de Raciocínio Lógico e APALINO. 